Review

\title{
Growing teratoma syndrome after surgery for ovarian immature teratoma
}

\author{
Soichiro Suzuki ${ }^{1, *}$, Yoshiaki Ota ${ }^{1}$, Rikiya Sano ${ }^{1}$, Yumiko Morimoto ${ }^{1}$, Takuya Moriya ${ }^{2}$, \\ Mitsuru Shiota ${ }^{1}$
}

${ }^{1}$ Department of Gynecologic Oncology, Kawasaki Medical School, 701-0192 Kurashiki, Okayama, Japan

${ }^{2}$ Department of Pathology, Kawasaki Medical School, 701-0192 Kurashiki, Okayama, Japan

*Correspondence: soichi731@med.kawasaki-m.ac.jp (Soichiro Suzuki)

Academic Editor: Kenjiro Sawada

Submitted: 20 November 2021 Revised: 4 January 2022 Accepted: 8 January 2022 Published: 15 February 2022

\begin{abstract}
Growing teratoma syndrome (GTS) is a condition characterized by tumor growth during or after chemotherapy for a germ cell tumor, albeit with normal tumor marker levels in the absence of histopathological evidence of immature teratoma components. We encountered a 10-cm large GTS lesion in the para-aorti nodes after fertility-preserving surgery for a grade 3 ovarian immature teratoma. The patient was a 20 year old woman who presented to the hospital with complaints of abdominal pain and swelling. Imaging examination revealed an ovarian tumor mass measuring $24 \mathrm{~cm}$ in the abdominal cavity, suspected to be composed of a mixture of fat and other components. The $\alpha$-fetoprotein (AFP) levels were elevated at $853 \mathrm{ng} / \mathrm{mL}$. We elected to perform fertility-preserving surgery. The surgical findings included a tumor in the right ovary, which was excised without rupture with adnexectomy. The histopathological diagnosis was grade 3 immature teratoma. Palpation of the pelvic and para-aortic lymph node areas did not reveal significant lymphadenopathy. Subsequently, a para-aortic node metastasis (major axis: $8 \mathrm{~cm}$ ) was discovered before chemotherapy (19 days after surgery). We confirmed that there was no swelling before surgery and assumed that the immature teratoma had recurred. Chemotherapy was initiated, and the serum AFP levels normalized after 4 courses of bleomycin, etoposide, and cisplatin (BEP) therapy. However, the para-aortic node metastasis had grown further (major axis: $10 \mathrm{~cm}$ ). Another open surgery was performed. The nodal mass was completely excised and pathology revealed only mature teratoma. Growing teratoma syndrome should be considered in the setting of a recurrent mass with negative tumor markers.
\end{abstract}

Keywords: Growing teratoma syndrome; Ovarian immature teratoma; BEP

\section{Introduction}

Growing teratoma syndrome (GTS), first reported in 1982, is a condition characterized by the presence and proliferation of mature teratoma components in metastatic lesions during chemotherapy for immature teratomas or mixed germ cell tumors [1]. In Japan, retroconversion [2] was first reported in the 1989 [3], and is considered to be the same disease concept as GTS.

Grade 3 immature teratoma is a rare disease accounting for $0.5 \%$ [4] of all ovarian malignancies. It is most common in younger women, who are at an age that warrants consideration of fertility preservation.

We encountered a 10-cm GTS in the para-aorti nodes after fertility-preserving surgery for a grade 3 ovarian immature teratoma. Herein, we report the clinical and therapeutic course in a young patient, along with a discussion of the literature.

\section{Case}

The patient was a 20-year old woman who presented with a chief complaint of abdominal pain and protrusion. She experienced menarche at 13 years of age. Her last menstrual cycle occurred 3 weeks before presentation. The length of the menstrual cycle was 30 days. She had a medical history of autonomic imbalance but her family history was unremarkable.

\subsection{Current disease history}

The patient first experienced abdominal distention 23 months prior to presentation. The abdominal protrusion and pain worsened, 2 weeks prior to presentation, which led her to consult a local doctor. Transabdominal ultrasonography revealed a cystic mass the size of an adult head, and the patient was referred to our hospital on the same day (Fig. 1). The maximal diameter of the lesion was $20 \mathrm{~cm}$ or more and the proportion of solid tissue was $10 \mathrm{~cm}$ or more. The lesion contained more than 10 cystic locules and some papillary projections and ascites. Magnetic resonance imaging (MRI) was performed at the outpatient clinic, but the abdominal pain made it difficult for the patient to remain in the supine position, which in turn rendered imaging impossible under outpatient care. She was admitted to the hospital for symptomatic relief and further examination.

\subsection{Condition at admission}

The patient was $149 \mathrm{~cm}$ tall and, weighed $48 \mathrm{~kg}$. Her vital statistics were as follows: blood pressure, 102/76 

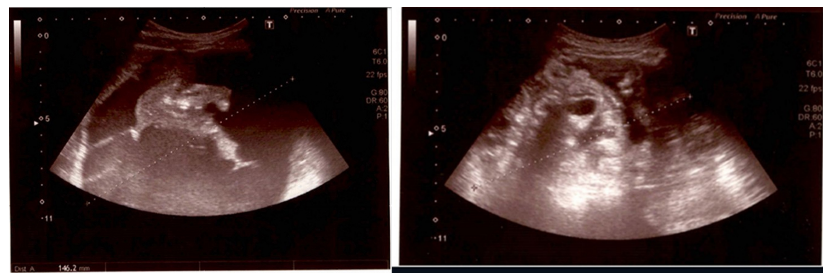

Fig. 1. Transabdominal ultrasound image. A mass with a mixture of cystic and solid components occupied the abdominal cavity.

$\mathrm{mmHg}$; pulse, regular 60 beats/min ; body temperature, $36.4{ }^{\circ} \mathrm{C}$. The abdomen exhibited generalized protrusion and a mass was palpable above the pubis and extended to the epigastric fossa.

Blood test findings (normal range in brackets):

$<$ Blood count $>$ WBC $8190 / \mu$ L (3300-8600), Hb 10.8 g/dL (11.6-14.8), Platelets 300,000/ $\mu \mathrm{L}$ (15800-34800)

$<$ Biochemistry > LDH 234 U/L (124-222), AST 17 U/L (13-30), ALT $8 \mathrm{U} / \mathrm{L}$ (7-23), Creatinine $0.57 \mathrm{mg} / \mathrm{dL}$ (0.46-0.79), CRP $10 \mathrm{mg} / \mathrm{dL}(0-0.14)$

$<$ Tumor markers $>$ AFP $853 \mathrm{ng} / \mathrm{mL}(0-10)$, SCC 3.0 ng/mL (0-1.5), CEA $1.5 \mathrm{ng} / \mathrm{mL}(0-5)$, CA125 35 U/mL (035), CA19-9 10.4 U/mL (0-37), STN $21.5 \mathrm{U} / \mathrm{mL}(0-45)$, HCG $1.3 \mathrm{mIU} / \mathrm{mL}(0-6)$

AFP and CRP levels showed marked elevation.

MRI depicted a multilocular tumor measuring approximately $118 \times 187 \times 220 \mathrm{~mm}$ with a variety of internal signal intensities, including solid and fat components, which suggested a germ cell tumor. It was not possible to identify whether the lesion originated from the left or right ovary (Fig. 2). Although preoperative MRI was acquired up to the upper abdomen, no swollen lymph nodes were found around the renal blood vessels at this juncture.

An ovarian immature teratoma was suspected before surgery. The tumor was resected 5 days after the first examination at our hospital.

\subsection{Surgical findings}

A tumor the size of an adult's head was found to occupy the abdominal cavity up to the upper abdomen. The border of the right ovary against the surrounding area was generally smooth, but adhesions to and invasion of the peritoneum near the suspensory ligament of the ovary were observed with the left ovary. Right sided adnexectomy, resection of the indurations on the abdominal wall side of the adhesions, omentectomy, and sampling of ascitic fluid were performed in order to preserve fertility. Palpation of the pelvic and para-aortic lymph node areas did not reveal significant lymphadenopathy. The extracted right adnexa measured $25 \mathrm{~cm}$ and weighed $3.1 \mathrm{~kg}$ (Fig. 3). The surgical grade was stage II, as per the 2014 International Federation of Gynecology and Obstetrics criteria.

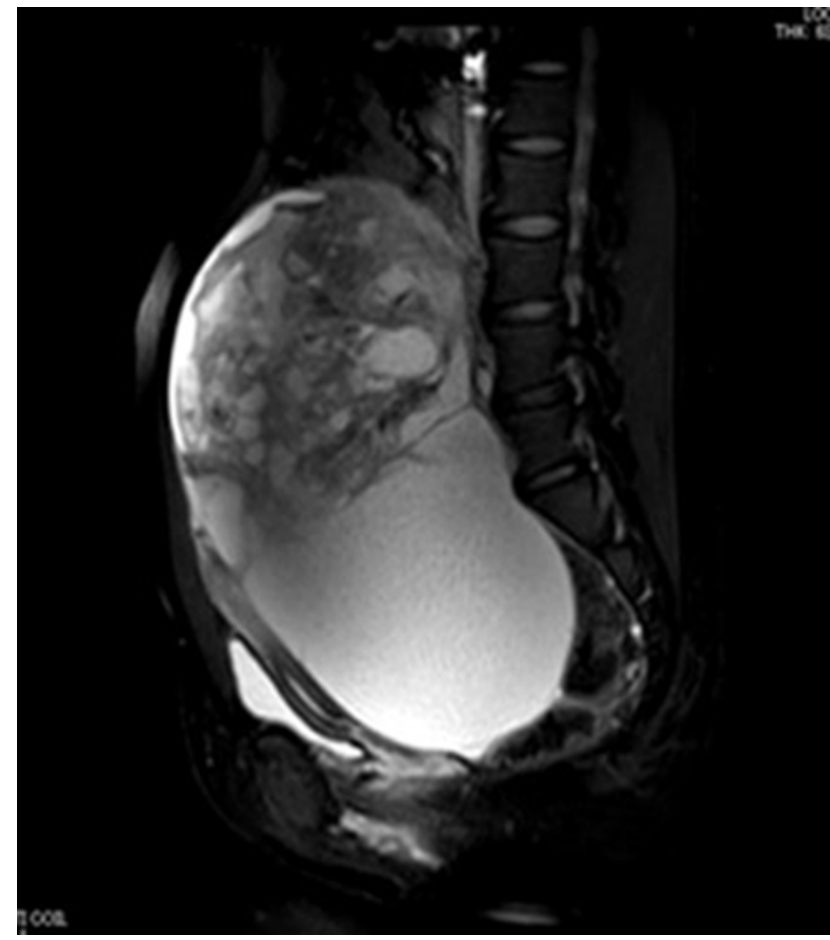

Fig. 2. MRI image. A large mass occupied the abdomen from the xiphoid process to the pelvic cavity. The interior consisted of a cyst component, a solid component, and a fat component.

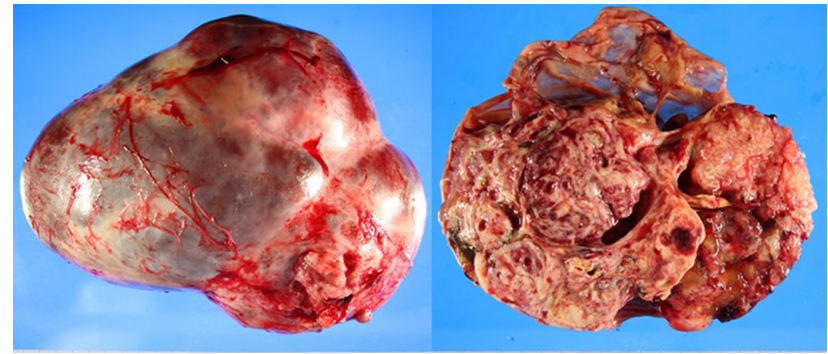

Fig. 3. Gross findings. The tumor was $25 \mathrm{~cm}$ and weighed 3.1 $\mathrm{kg}$. The surface was relatively smooth, and a solid component was found inside the cyst with multiple septa. Findings indicating necrosis were found in the solid part.

\subsection{Histopathological findings}

Immature tissue containing skin, airway epithelium, cartilage, bone, adipose tissue, nerve tissue, choroid plexus, melanin-containing cells, gastrointestinal tract tissue, and neural tubes spanned multiple fields of view, as observed under a $4 \times$ objective lens. The histopathological diagnosis was grade 3 ovarian immature teratoma (Fig. 4). The main lesion and the adhesion lesion showed similar findings. There was a local invasion in the adhesion. There was no abnormality in the ascites and omentum.

Contrast-enhanced computed tomography (CT) performed immediately before chemotherapy (19 days after surgery) revealed para-aorti node metastasis $(81 \times$ $25 \times 30 \mathrm{~mm}$ ) that had not been observed in preoper- 


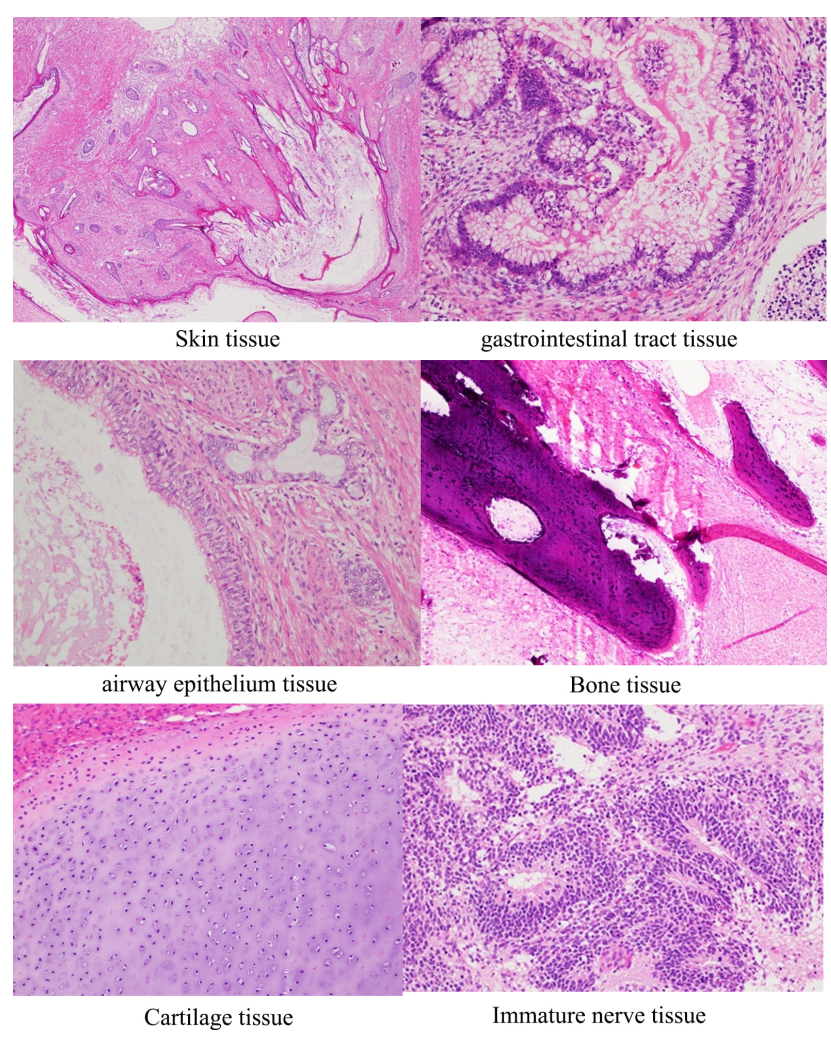

Fig. 4. The tumor was composed of immature tissues containing multiple germ layer components, and the immature nerve components could be easily confirmed in multiple visual fields in a quadruple visual field.

ative imaging (Fig. 5). Chemotherapy was prioritized because susceptibility to chemotherapy was presumed. Bleomycin, etoposide, and cisplatin (BEP) therapy was administered for postoperative chemotherapy, after obtaining sufficient induction chemotherapy, and assessing the risk of ovarian toxicity. Four courses of the following BEP regimen were administered: bleomycin $(30 \mathrm{mg} / \mathrm{body}$ weight/day) was administered on days 2,9 and 16, etoposide $\left(100 \mathrm{mg} / \mathrm{m}^{2} /\right.$ day) was administered on days $1-5$, and cisplatin $\left(20 \mathrm{mg} / \mathrm{m}^{2} /\right.$ day) was administered on days $1-5$. Gonadotrophin-releasing hormone $(\mathrm{GnRH})$ analogues and oral contraceptives reportedly suppress ovarian function to protect against the ovarian toxicity of anticancer drugs [57]. Thus, GnRH agonists were used until the end of BEP therapy. Dehydration, hypotension, and facial contusion were observed due to the daily administration of diuretics, which improved after infusion and antibiotic use. No interstitial pneumonia or secondary leukemia was observed during the treatment period.

The patient's sample tested negative for AFP after the third course of BEP and remained negative thereafter (Fig. 6), although contrast-enhanced CT performed after chemotherapy showed further enlargement of the paraaortic nodes $(101 \times 57 \times 51 \mathrm{~mm})$ (Fig. 7). The differential diagnosis included recurrence of immature teratoma, malig-

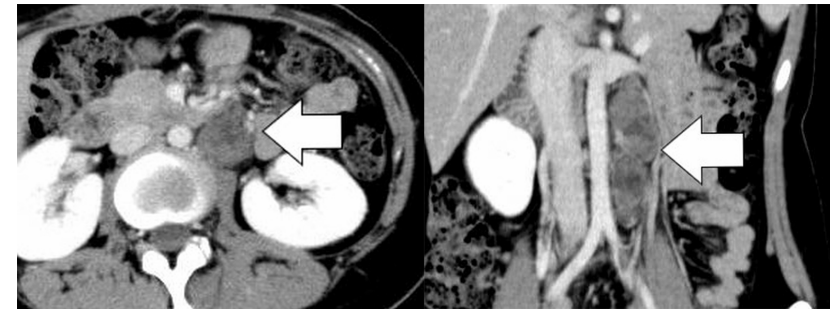

Fig. 5. A tumor $(81 \times 25 \times 30 \mathrm{~mm})$ was found on the left side of the abdominal aorta and just below the left renal artery.

nant transformation of the teratoma components, and GTS. GTS had the strongest likelihood because of recurrence in the para-aortic lymph nodes after surgery, normalization of blood tumor markers, and growth of a metastatic lesion during or after chemotherapy. We decided to remove the tumor due to signs of exclusion of the left renal blood vessels.

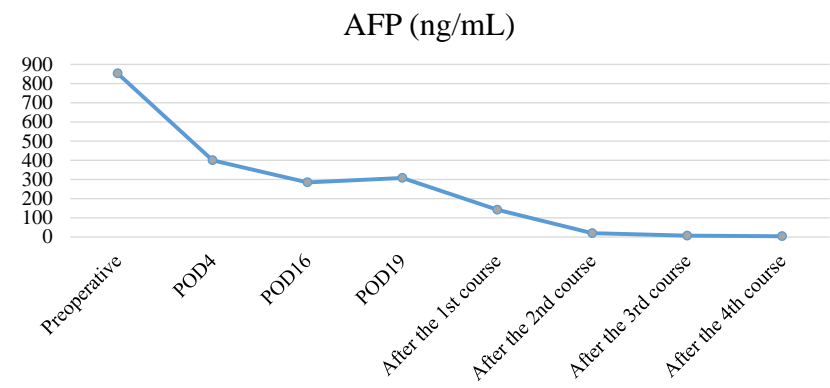

Fig. 6. Transition of AFP.

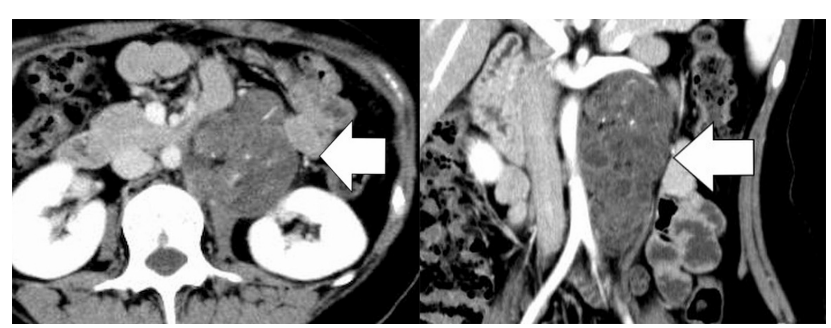

Fig. 7. The mass had grown $(101 \times 57 \times 51 \mathrm{~mm})$ and was compressing the abdominal aorta and the renal artery just above it.

Blood tumor markers after chemotherapy: <AFP 4.8 $\mathrm{ng} / \mathrm{mL}(0-10)$, SCC $1.1 \mathrm{ng} / \mathrm{mL}(0-1.5)$, CEA $2.3 \mathrm{ng} / \mathrm{mL}$ (0-5), CA125 9 U/mL (0-35), CA19-9 $23.3 \mathrm{U} / \mathrm{mL}(0-37)$, HCG $2.3 \mathrm{mIU} / \mathrm{mL}(0-6)>$

A second open surgery was performed for complete removal of the tumor. The operative time was $3 \mathrm{~h} 43$ min and the amount of blood loss was $150 \mathrm{~mL}$ (Fig. 8). Histopathological findings showed no immature nerve tissue and the diagnosis was grade 0 (Fig. 9). 


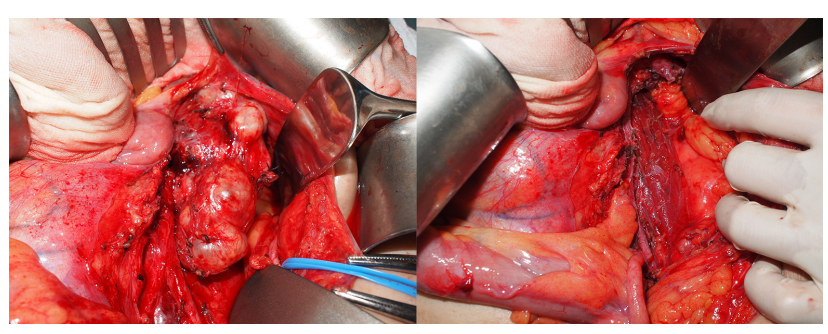

Fig. 8. This is a photograph of the retroperitoneum expanded. A mass with fused multiple nodules was found. Many inflow vessels were observed, but the boundaries were relatively clear. The right photograph shows the retroperitoneum after removal of the tumor.

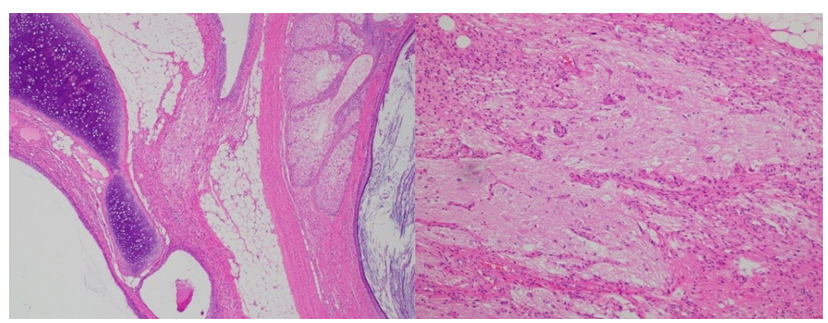

Fig. 9. Excised para-aortic lymph nodes. On left, the skin, cartilage, and multi-row ciliated epithelium are shown. On the right is nerve tissue, and no immature tissue was found in any of histological specimens.

The patient was placed under observation without any further treatment. At present, 15 months have elapsed since the removal of the GTS lesion, and no recurrence has been observed, as evidenced by tumor markers levels and contrast-enhanced CT. However, menstruation did not resume even 6 months after the end of chemotherapy. A blood test revealed reduced estradiol and increased follicle stimulating hormone levels. Hormone replacement therapy was initiated considering the risk of bone mineral loss and uterine atrophy.

\section{Discussion}

It is vital to initiate chemotherapy soon after surgery for ovarian germ cell tumors [8], owing to the rapid growth of malignant germ cell tumors. An 8-cm large para-aortic node metastasis that was not observed preoperatively was found immediately before postoperative chemotherapy (19 days after surgery) in our patient, which was attributed to the development of GTS in this area. The speed at which the grade 3 immature teratoma proliferated in our patient demonstrates the need for initiating chemotherapy soon after surgery.

Follow-up is essential after the treatment of immature teratomas due to the possibility of GTS. CT, MRI, and positron emission tomography (PET-CT) are the avail- able imaging options, although PET-CT is not suitable for determining whether a lesion is benign or malignant because it reportedly depicts accumulations due to glucose metabolism in the nerve cells of teratomas $[9,10]$.

The diagnostic criteria for GTS include normalization of blood tumor markers, growth of metastatic lesions during or after chemotherapy, and the histological presence of mature teratoma components [1]. An advanced stage III tumor, insufficient tumor reduction during surgery, and the presence of immature teratoma components in the primary tumor constitute the risk factors for GTS [11]. GTS does not respond to chemotherapy and can be the origin of secondary tumors. Surgical resection is performed to relieve pressure on surrounding organs [1].

Three differential diagnoses were possible in this case:

(1) GTS with an increased mature teratoma component, (2) increased immature teratoma component due to ineffective BEP therapy, and (3) secondary tumor caused by the teratoma component. Organ damage due to pressure on surrounding organs due to GTS was considered. Chemotherapy is a therapeutic option for residual immature teratoma, but is ineffective for GTS. Moreover, chemotherapy may have adverse effects such as ovarian toxicity and reduced quality of life. Thus, we think that tissue diagnosis should be prioritized in such cases.

We found 52 cases of GTS or retroconversion occurring after ovarian immature teratoma since 1987 (Table 1, Ref. [3,8-10,12-54]). We examined all 53 cases, including the present one. The mean age at initial onset of the immature teratoma was 20.8 years (median 19 years), and two patients underwent emergency surgery for acute abdomen due to torsion. A woman who was diagnosed at 18 weeks' gestation underwent termination of pregnancy. The mean AFP level before initial treatment was $4844 \mathrm{ng} / \mathrm{mL}$ (median: $900 \mathrm{ng} / \mathrm{mL}$ ). All patients underwent postoperative chemotherapy: 31 with BEP and 6 with vinblastine, actinomycin D, and cyclophosphamide (VAC). The mean duration from treatment of the immature teratoma to the development of GTS was 39.9 months (median 12.0 months), the longest being 16 years, which shows the necessity of longterm follow-up. The most common location of the GTS lesion was peritoneal dissemination in 25 patients, followed by the para-aorti nodes in 5 patients, and the lungs in 2 patients, liver in 6 patients, and contralateral ovary in 2 patients each. Eight studies reported that patients underwent chemotherapy despite having suspected GTS. One patient was administered 12 courses of chemotherapy.

Since 2012, there have been 7 reports of laparoscopic biopsy for suspected GTS, which is considered to be a useful and minimally invasive approach for obtaining a definitive diagnosis in cases where GTS is strongly suspected. 
Table 1. Previous reports of GTS.

\begin{tabular}{|c|c|c|c|c|c|c|c|c|}
\hline Author & Year reported & Grade & AFP & Initial chemotherapy & No. of courses & $\begin{array}{l}\text { Age at } \\
\text { onset }\end{array}$ & $\begin{array}{l}\text { Time from initial treatment } \\
\text { to development of } \\
\text { suspected GTS (months) }\end{array}$ & GTS site \\
\hline Kaneko [3] & 1989 & 3 & 29873 & VAC & 4 & 14 & 13 & PAN \\
\hline Miyasaka et al. [12] & 1991 & 3 & 200 & VAC & 4 & 14 & 114 & Peritoneal dissemination \\
\hline Nakagawa et al. [13] & 1991 & 2 & Unknown & Chemo + radiation & Unknown & 31 & 14 & Lungs: 10 years follow-up \\
\hline Yakushiji et al. [14] & 1994 & 2 & About 140 & VAC & 8 & 12 & 24 & Peritoneal dissemination \\
\hline Masuko et al. [15] & 1995 & Unknown & Unknown & VAC & Unknown & 24 & 139 & Peritoneal dissemination \\
\hline Higaki et al. [16] & 1997 & Unknown & Unknown & VAC & 9 & 15 & 36 & Peritoneal dissemination, liver (left for 8 years) \\
\hline Kobayashi et al. [17] & 1999 & 1 & Unknown & VAC & 4 & 19 & 14 & Peritoneal dissemination \\
\hline Kumagaya et al. [18] & 2000 & 1 & 166 & Other & 2 & 11 & 77 & Contralateral ovary \\
\hline Sakurai et al. [19] & 2001 & 3 & Unknown & Other & Unknown & 17 & 156 & Peritoneal dissemination \\
\hline Itani et al. [20] & 2002 & 2 & 21236 & Other & 3 & 24 & 4 & PAN \\
\hline Tagaya et al. [21] & 2003 & 2 & 188 & BEP & Unknown & 21 & 2 & Peritoneal dissemination \\
\hline Rai et al. [22] & 2004 & 3 & 2530 & Other & 5 & 15 & 12 & PAN \\
\hline Furudo et al. [23] & 2004 & 3 & 2642 & BEP & 2 & 19 & 48 & Peritoneal dissemination \\
\hline Sunagawa et al. [24] & 2007 & 2 & 397 & Other & 2 & 13 & 96 & Peritoneal dissemination \\
\hline Totake et al. [25] & 2011 & 2 & 244 & BEP & 4 & 13 & 3 & Peritoneal dissemination \\
\hline Adachi et al. [26] & 2010 & 2 & 12400 & Other & 3 & 18 & 192 & Contralateral ovary, peritoneal dissemination \\
\hline Kikawa et al. [9] & 2011 & 2 & 11 & BEP & 3 & 36 & 8 & Peritoneal dissemination \\
\hline Terada et al. [27] & 2013 & 1 & 28 & BEP & 3 & 20 & 5 & Peritoneal dissemination \\
\hline Abe et al. [28] & 2012 & 3 & 4344 & BEP & 6 & 37 & 5 & Peritoneal dissemination \\
\hline Mariya et al. [29] & 2013 & Unknown & 1134 & BEP & 3 & 30 & 26 & Peritoneal dissemination \\
\hline Morita et al. [30] & 2014 & 3 & 1121 & BEP & 4 & 26 & 78 & Peritoneal dissemination \\
\hline Imai et al. [31] & 2014 & 1 & 18743 & BEP & 4 & 11 & 6 & Peritoneal dissemination \\
\hline Hayashi et al. [32] & 2015 & Unknown & 1052 & BEP & 4 & 41 & 5 & Peritoneal dissemination \\
\hline Sakamoto et al. [33] & 2015 & 2 & 23352 & BEP & 3 & 11 & 6 & Peritoneal dissemination \\
\hline Ando et al. [34] & 2015 & 3 & 1239 & BEP & 4 & 19 & 5 & Peritoneal dissemination \\
\hline Umezu et al. [35] & 2015 & 2 & 2924 & BEP & 4 & 29 & 72 & Peritoneal dissemination \\
\hline Kojima et al. [36] & 2019 & 1 & 288 & BEP & 3 & 18 & 3 & Peritoneal dissemination \\
\hline Tanaka et al. [37] & 2020 & 2 & Unknown & BEP & 3 & 21 & 3 & Peritoneal dissemination \\
\hline Nakamura et al. [38] & 2020 & 3 & 35464 & BEP & 4 & 24 & 4 & Peritoneal dissemination \\
\hline Byrd et al. [39] & 2013 & 1 & Unknown & BEP & Unknown & 48 & 132 & Uterus \\
\hline
\end{tabular}


Table 1. Continued.

\begin{tabular}{|c|c|c|c|c|c|c|c|c|}
\hline Author & $\begin{array}{l}\text { Year } \\
\text { reported }\end{array}$ & Grade & AFP & Initial chemotherapy & No. of courses & $\begin{array}{l}\text { Age at } \\
\text { onset }\end{array}$ & $\begin{array}{l}\text { Time from initial treatment } \\
\text { to development of } \\
\text { suspected GTS (months) }\end{array}$ & GTS site \\
\hline Daher et al. [40] & 2015 & 3 & Elevated & etoposide, ifosfamide, and cisplatin & Unknown & 4 & 7 & $\begin{array}{l}\text { Pelvic, omentum, appendix, broad } \\
\text { ligament, abdominal wall }\end{array}$ \\
\hline Djoordjevic et al. [41] & 2007 & 3 & 2839 & Unknown & Unknown & 19 & 7 & $\begin{array}{c}\text { Periaortic, peripancreatic, perisplenic, } \\
\text { omental, transverse colon, sigmoid, } \\
\text { mesenteric }\end{array}$ \\
\hline Han et al. [8] & 2014 & Unknown & Elevated & BEP & Unknown & 13 & 5 & Pelvic \\
\hline Han et al. [8] & 2014 & Unknown & Elevated & BEP & Unknown & 13 & 16 & perihepatic space, pelvic \\
\hline Han et al. [8] & 2014 & Unknown & Elevated & BEP & Unknown & 27 & 83 & $\begin{array}{l}\text { subphrenic space, space, splenic hilum, } \\
\text { paracolic gutter, rectouterine pouch }\end{array}$ \\
\hline Hariprasad et al. [42] & 2008 & 3 & 560 & BEP & 4 & 18 & 11 & $\begin{array}{l}\text { abdomino pelvic, uterus, rectum, sigmoid } \\
\text { colon }\end{array}$ \\
\hline Hariprasad et al. [42] & 2008 & 3 & 1462 & BEP & 4 & 26 & Unknown & pelvic \\
\hline Hariprasad et al. [42] & 2008 & Unknown & 6000 & BEP & 4 & 27 & Unknown & pelvic, liver \\
\hline Kampan et al. [43] & 2012 & 1 & Unknown & Unknown & Unknown & 17 & 12 & Bilateral adnexal, utarus \\
\hline Kato et al. [44] & 2013 & 3 & Normal & BEP & Unknown & 30 & 96 & retroperitoneum, nodules in pelvicavity \\
\hline Kato et al. [44] & 2013 & 3 & Normal & vincristin, actinomycin $\mathrm{D}$, carbonin & Unknown & 22 & 264 & peritoneal cavity \\
\hline kurata et al. [45] & 2010 & 2 & 107 & non & Unknown & 15 & 19 & brain, liver, lung \\
\hline Lorusso et al. [46] & 2011 & 3 & 105 & BEP & 4 & 19 & 4 & liver \\
\hline Matsushita et al. [10] & 2010 & 2 & 343 & BEP & 4 & 30 & 97 & superior pole of kidney \\
\hline Morency et al. [47] & 2012 & 3 & 400 & BEP & 4 & 20 & 18 & pelvic, liver \\
\hline Mrabti et al. [48] & 2011 & Unknown & 210 & etoposide, cisplatin & 6 & 18 & 6 & abdmino pelvi, peritoneum \\
\hline Pendlebury et al. [49] & 2014 & 3 & 86 & etoposide, cisplatin & 2 & 21 & 2 & $\begin{array}{l}\text { Serosal surface of liver, hemidiaphragm, } \\
\text { pelvic peritoneum }\end{array}$ \\
\hline Rashmi et al. [50] & 2010 & 3 & 5378 & Unknown & 3 & 19 & 36 & Omentum, peritoneum, bowel loops \\
\hline Sengar et al. [51] & 2010 & 1 & 265 & BEP & 3 & 26 & 4 & pelvic, abdominal wall \\
\hline Tangitgamol et al. [52] & 2006 & 3 & 900 & BEP & 2 & 5 & 5 & Mass beneath diaphragm \\
\hline Tejura [53] & 2005 & Unknown & 154 & Unknown & Unknown & 21 & 12 & pelvic, adnexal, para-aortic lymph \\
\hline Tzortzatos et al. et al. [54] & 2009 & 2 & Unknown & BEP & 3 & 20 & 24 & Sacrouterina ligaments, fossa douglasi \\
\hline Present case & 2019 & 3 & 853 & BEP & 4 & 20 & 5 & PAN \\
\hline average & & & 4844 & & & 20.7 & 39.9 & \\
\hline mean & & & 900 & & & 19 & 12 & \\
\hline
\end{tabular}

PAN, Para-aortic lymph nodes; BEP, bleomycin, etoposide, cisplatin; VAC, vinblastine, actinomycin D, cyclophosphamide; AFP, $\alpha$-fetoprotein; GTS, Growing teratoma syndrome. 


\section{Conclusions}

Tumorous lesions that develop after treatment for immature teratoma should be carefully examined for the possibility of GTS. Tissue diagnosis should be pursued aggressively since surgery is the only treatment modality for GTS.

\section{Author contributions}

SS, YO, RS, YM, MS collected clinical data. TM collected histological data. SS, RS, YM compiled information collection and data on past reports. YO, TM, MS advised on the design of the paper. All authors contributed to editorial changes in the manuscript. All authors read and approved the final manuscript.

\section{Ethics approval and consent to participate}

$$
\text { Not applicable. }
$$

\section{Acknowledgment}

We would like to express our gratitude to all those who helped us during the writing of this manuscript. Thanks to all the peer reviewers for their opinions and suggestions.

\section{Funding}

This research received no external funding.

\section{Conflict of interest}

The authors declare no conflict of interest.

\section{References}

[1] Logothetis CJ, Samuels ML, Trindade A, Johnson DE. The growing teratoma syndrome. Cancer. 1982; 50: 1629-1635.

[2] Amsalem H. Growing teratoma syndrome vs. chemotherapeutic retroconversion Case report and review of the literature. Gynecologic Oncology. 2004; 92: 357-360.

[3] Aoki D. Annual report of Gynecologic Oncology Committee, Japan Society of Obstetrics and Gynecology, 2013. Journal of Obstetrics and Gynaecology Research. 2014; 40: 338-348.

[4] Kikawa S, Todo Y, Minobe S, Yamashiro K, Kato H, Sakuragi $\mathrm{N}$. Growing teratoma syndrome of the ovary: a case report with FDG-PET findings. The Journal of Obstetrics and Gynaecology Research. 2011; 37: 926-932.

[5] Matsushita H, Arai K, Fukase M, Takayanagi T, Ikarashi H. Growing teratoma syndrome of the ovary after fertility-sparing surgery and successful pregnancy. Gynecologic and Obstetric Investigation. 2010; 69: 221-223.

[6] Zagamé L, Pautier P, Duvillard P, Castaigne D, Patte C, Lhommé C. Growing teratoma syndrome after ovarian germ cell tumors. Obstetrics and Gynecology. 2006; 108: 509-514.

[7] Kaneko H, Somekawa Y, Kuwae C, Shida T, Kitada H, Ohotsuka $\mathrm{H}$. A case of Retroconversion of Ovarian Immature Teratoma. Tokyo Journal of Obstetrics and Gynecology. 1989; 38: 13-16.

[8] Miyasaka N, Kubota N, Kawamura T, Ozaki Y, Shimizu Y, Shimizu K, Aso T. A case of ovarian immature teratoma showing the retroconversion. Obstetrics and Gynecology. 1991; 58: 1395-1399.

[9] Nakagawa K, Iwasaki T, Okada T, Nozaki T, In K, Okumura M, Kotake Y, Yasumitu T, Katsumoto Y, Nakagawa T, Morino H, Kikui M. The Japanese Journal of Thoracic Surgery. 1991; 44: 856-859.
[10] Yakushiji H, Miyazaki K, Mashima H, Hisatsugu T, Sasatomi E. A case of retroconversion in metastasis of the diaphragm from ovarian immature teratoma. The Journal of the Japanese Practical Surgeon Society. 1994; 55: 1771-1774.

[11] Masuko Y, Arai H. A case of retroconversion in metastasis of the peritoneum and the liver from ovarian teratoma. Journal of Japan Surgical Association. 1995; 50: 665-670.

[12] Higaki I, Mizukami K, Hirata S, Fujimoto Y, Yamazaki O, Okuno M. A surgical case of peritoneal dissemination with retroconversion of ovarian immature teratoma. The Journal of the Japanese Practical Surgeon Society. 1997; 58: 1370-1373.

[13] Kobayashi J, Kobayashi M, Iwagaki H. Teratomatosis Peritonei Originated From An Immature Ovarian Teratoma-A Completely Cured Case With Six Operations. Journal of Japan Surgical Association. 1999; 60: 210-215.

[14] Kumagai K, Kanda K, Sato N, Iwai E, Ueki K, Terai Y, et al. A Case fo Left Ovarian Mature Cystic Teratoma Following Surgery and Chemotherapy for the Right Ovarian Immature Teratoma. The Journal of Obstetrics and Gynaecology. 2000; 52: 1717-1720.

[15] Sakurai Y, Miyakita M, Furukawa J, Ishikawa Y, Yoshitake A, Nishikawa M. A resected case of isolated peritoneal dissemination between the surface of liver and the diaphagma from ovarian immature teratoma. Journal of Japan Surgical Association. 2001; 56: 1125-1129.

[16] Itani Y, Kawa M, Toyoda S, Yamagami K, Hiraoka K. Growing teratoma syndrome after chemotherapy for a mixed germ cell tumor of the ovary. The Journal of Obstetrics and Gynaecology Research. 2002; 28: 166-171.

[17] Tagaya H, Kasai T, Honda T, Kobayashi Y, Hagiwara S, Komuro M, et al. A Case of Growing Teratoma Syndrome During Chemotherapy for Immature Teratome of the Ovary. Kanto Journal of Obstetrics and Gynecology. 2003; 40: 11-16.

[18] Rai E, Akagi T, Hayama T, Iwamoto T. Growing teratoma syndrome after chemotherapy for an immature teratoma of the right ovary. Obstetrics and Gynecology. 2004; 71: 816-820.

[19] Furudo T, Nagashima K, Katakiri H, Nakasato T. A case of immature teratoma with Pseudo-Meigs syndrome and Growing Teratoma syndrom. Obstetrics and Gynecology. 2004; 71: $1243-1247$.

[20] Sunagawa M, Katoh T, Suzuki M, Shibata Y, Hiramatsu K, Shinohara T. A case of right subphrenic growing teratoma syndrome secondary to immature teratoma of the ovary. Journal of Japan Surgical Association. 2007; 68: 1816-1820.

[21] Totake K, Ando N, Ogawa K, Maeda O, Tokunaka M, Arakawa $\mathrm{K}$, et al. A case report of growing teratoma syndrome after treatment for ovarian immature teratoma. The Kanagawa District Journal of the Japanese Obstetrical and Gynecological Society. 2011; 47: 129-132.

[22] Adachi K, Watanabe M, Kanayama T, Ogata S, Amemiya K, Yokoi $\mathrm{T}$, et al. A case of growing teratoma syndrome managed by laparoscopic surgery. Japanese Journal of Gynecologic and Obstetric Endoscopy. 2010; 26: 370-373.

[23] Terada K, Yamagishi E, Kawabata I, Nakao K, Kuwabara T, Inde Y, et al. Growing Teratoma Syndrome during Chemotherapy for Immature Teratoma of the Ovary with Glimatosis Peritonei. Tokyo Journal of Obstetrics and Gynecology. 2013; 62: 76-80.

[24] Abe A, Utsugi K, Nomura H, Matoda M, Omatsu K, Kato K, et $a l$. A case of ovarian growing teratoma syndrome successfully treated with laparoscopy. Japanese Journal of Gynecologic and Obstetric Endoscopy. 2012; 28: 521-525.

[25] Mariya T, Nishikawa A, Numata K, Kawamata A, Nihei T, Saito T. Laparoscopic Resection of Growing Teratoma Syndrome PostChemotherapy for an Immature Ovarian Teratoma: Case Report. Japanese Journal of Gynecologic and Obstetric Endoscopy. 2013; 29: 158-162. 
[26] Morita T, Masahiro S, Koike H, Hirano Y, Sakaguchi Y, Niguma $\mathrm{T}$. A case of growing teratoma syndrome: laparoscopic resection of primary immature teratoma. Modern Trends in Obstetrics \& Gynecology. 2014; 63: 95-99.

[27] Imai T, Sakon H, Nishizawa C, Iidaka M, Hara Yousuke, Takata $\mathrm{M}$, Mori A. A case of growing teratoma syndrome after ovarian mixed germ cell tumor. Kanto Journal of Obstetrics and Gynecology. 2014; 51: 593-596.

[28] Hayashi H, Taniguchi S, Kurihara S, Nakatake Y, Hachisuka K, Nakano T, et ak. A case of Growing Teratoma Syndrome Diagnosed by Laparoscopic Surgery after Chemotherapy for Malignant Ovarian Germ Cell Tumor. The Journal of the Miyazaki Medical Association. 2015; 39: 39-44.

[29] Sakamoto S, Hashizume N, Yagi M, Asagiri K, Fukahori S, Kojima S, et ak. Treatment of Growing Teratoma Syndrome From Ovarian and Peritoneal Disseminational Teratoma: A Case Report. Journal of the Japanese Society of Pediatric Surgeons. 2015; 51: 1214-1219.

[30] Ando Y, Kawashima N, Tokushige Y, Ikeda A, Takamatsu S, Murata $\mathrm{Y}$, et al. A case of ovarian growing teratoma syndrome diagnosed and treated using laparoscopic surgery. Japanese Journal of Gynecologic and Obstetric Endoscopy. 2015; 31: 232-237.

[31] Umezu T, Osafune A, Inukai K, Mogi K, Aoki C, Yamada C, Matsui J. A case of growing teratoma syndrome managed by laparoscopic surgery 14 years after the first therapy. The Tokai Journal of Obstetrics and Gynecology. 2016; 52: 175-179.

[32] Kojima M, Kato A, Watanabe T, Okabe C, Sato T, Miura H, et al. A case of growing teratoma syndrome that deveroped after treatment for ovarian immature teratoma and was treated by laparoscopic surgery. Fukushima Medical Journal. 2019; 69: 712.

[33] Tanaka H, Onishi J, Goto Y, Matsuzawa S, Fuzzisaki M, Fukushima $\mathrm{K}$, et al. Growing teratoma syndrome secondary to peritoneum dissemination of ovarian immature teratoma : A case report. The Journal of the Miyazaki Medical Association. 2020; 44: 25-29.

[34] Nakamura S, Kusumoto T, Terabayashi H, Kojima K, Funatomi $\mathrm{S}$, Nishimura $\mathrm{T}$, et al. A case of growing teratoma syndrome during chemotherapy for ovarian immature teratoma. Modern Trends in Obstetrics \& Gynecology. 2020; 69: 101-105.

[35] Byrd K, Stany MP, Herbold NC, Leath CA, Hamilton CA. Growing teratoma syndrome: Brief communication and algorithm for management. The Australian \& New Zealand Journal of Obstetrics \& Gynaecology. 2013; 53: 318-321.

[36] Daher P, Riachy E, Khoury A, Raffoul L, Ghorra C, Rehayem C. Growing teratoma syndrome: first case report in a 4-year-old girl. Journal of Pediatric and Adolescent Gynecology. 2015; 28: e5-e7.

[37] Djordjevic B, Euscher ED, Malpica A. Growing teratoma syndrome of the ovary: review of literature and first report of a carcinoid tumor arising in a growing teratoma of the ovary. The American Journal of Surgical Pathology. 2007; 31: 1913-1918.

[38] Han NY, Sung DJ, Park BJ, Kim MJ, Cho SB, Kim KA, et al. Imaging features of growing teratoma syndrome following a malignant ovarian germ cell tumor. Journal of Computer Assisted
Tomography. 2014; 38: 551-557.

[39] Hariprasad R, Kumar L, Janga D, Kumar S, Vijayaraghavan M. Growing teratoma syndrome of ovary. International Journal of Clinical Oncology. 2008; 13: 83-87.

[40] Kampan N, Irianta T, Djuana A, Pei Shan L, Hashim Omar M, Hatta Mohd Dali AZ. Growing teratoma syndrome: a rare case report and review of the literature. Case Reports in Obstetrics and Gynecology. 2012; 2012: 134032.

[41] Kato N, Uchigasaki S, Fukase M. How does secondary neoplasm arise from mature teratomas in growing teratoma syndrome of the ovary? A report of two cases. Pathology International. 2013; 63: 607-610.

[42] Kurata A, Hirano K, Nagane M, Fujioka Y. Immature teratoma of the ovary with distant metastases: favorable prognosis and insights into chemotherapeutic retroconversion. International Journal of Gynecological Pathology. 2010; 29: 438-444.

[43] Lorusso D, Malaguti P, Trivellizzi IN, Scambia G. Unusual liver locations of growing teratoma syndrome in ovarian malignant germ cell tumors. Gynecologic Oncology Case Reports. 2013; 1: 24-25.

[44] Morency EG, Lerner D, Garcia R, Kalir T. High-grade sarcoma masquerading as growing teratoma syndrome after resection of ovarian immature teratoma: report of a case. International Journal of Gynecological Pathology. 2012; 31: 276-279.

[45] Mrabti H, El Ghissassi I, Sbitti Y, Amrani M, Hachi H, Errihani H. Growing teratoma syndrome and peritoneal gliomatosis. Case Reports in Medicine. 2011; 2011: 123527.

[46] Pendlebury A, Rischin D, Ireland-Jenkin K, Toner GC, Grant P. Ovarian Growing Teratoma Syndrome with Spuriously Elevated $\alpha$-Fetoprotein. Journal of Clinical Oncology. 2014; 33: e99-100.

[47] Rashmi, Radhakrishnan G, Radhika AG, Sharma S. Growing teratoma syndrome: a rare complication of germ cell tumors. Indian Journal of Cancer. 2010; 47: 486-487.

[48] Sengar AR, Kulkarni JN. Growing teratoma syndrome in a post laparoscopic excision of ovarian immature teratoma. Journal of Gynecologic Oncology. 2010; 21: 129-131.

[49] Tangjitgamol S, Manusirivithaya S, Leelahakorn S, Thawaramara T, Suekwatana P, Sheanakul C. The growing teratoma syndrome: a case report and review of the literature. International Journal of Gynecological Cancer. 2006; 16: 384-390.

[50] Tejura H, O'Leary A. Growing teratoma syndrome after chemotherapy for germ cell tumour of the ovary. Journal of Obstetrics and Gynaecology. 2005; 25: 296-297.

[51] Tzortzatos G, Sioutas A, Schedvins K. Successful pregnancy after treatment for ovarian malignant teratoma with growing teratoma syndrome. Fertility and Sterility. 2009; 91: 936.e1936.e3.

[52] Meistrich ML, Shetty G. Hormonal suppression for fertility preservation in males and female. Reproduction. 2008; 136: 691-701.

[53] Blumenfeld Z. GnRH-agonists in fertility preservation. Current Opinion in Endocrinology, Diabetes, and Obesity. 2008; 15: 523-528.

[54] Weinberg LE, Lurain JR, Singh DK, Schink JC. Survival and reproductive outcomes in women treated for malignant ovarian germ cell tumors. Gynecologic Oncology. 2011; 121: 285-289. 